\title{
Resection of pancreatic head neoplasm in a patient with previous coronary bypass grafting using right gastroepiploic artery
}

\author{
Takahisa Fujikawa, ${ }^{1}$ Tomohiro Noda, ${ }^{1}$ Yoshio Arai, ${ }^{2}$ Akira Tanaka ${ }^{1}$
}

${ }^{1}$ Department of Surgery, Kokura Memorial Hospital, Kitakyushu, Japan

${ }^{2}$ Department of Cardiovascular Surgery, Kokura Memorial Hospital, Kitakyushu, Japan

\section{Correspondence to} Dr Takahisa Fujikawa, fujikawa-t@kokurakinen.or.jp

Accepted 25 May 2014
CrossMark

\begin{tabular}{l}
\hline To cite: Fujikawa T, Noda T, \\
Arai Y, et al. BMJ Case Rep \\
Published online: [please \\
include Day Month Year] \\
doi:10.1136/bcr-2014- \\
204132
\end{tabular}

\section{DESCRIPTION}

A 64-year-old man was admitted for assessment and management of pancreatic head tumour. He had a history of angina pectoris which was treated by coronary artery bypass grafting (CABG) using the pedicled right gastroepiploic artery (RGEA) 7 years ago. His follow-up CT scan revealed a $4 \mathrm{~cm}$-sized multilocular cystic tumour of the pancreatic head, which was gradually enlarging during 2 years and was suggestive of potentially malignant intraductal papillary mucinous tumour (IPMN), without evidence of distant metastasis (figure 1A, B). Coronary CT showed the patent RGEA graft connected to the right coronary artery (RCA) (figure $1 \mathrm{C}$, video A). After discussing how best to manage intraoperative coronary vascular flow by surgeons, cardiovascular surgeons and cardiologists, the decision was finally made that "non-drug eluting" coronary stent implantation (CSI) to the RCA was preceded, and resection of the tumour under continuation of single antiplatelet therapy with aspirin was scheduled. Following successful native coronary revascularisation, subtotal stomach preserving pancreaticoduodenectomy (PD) by sacrificing RGEA was satisfactorily performed without any intraoperative cardiac complications (video B). Pathologically, the tumour was diagnosed IPMN with moderate atypia. He recovered soon postoperatively without any bleeding or thromboembolism, and was discharged on postoperative day 20. The usefulness of RGEA for CABG has been widely studied, but interruption of RGEA used for prior CABG may cause life-threatening myocardial ischaemia during upper abdominal surgery. A detailed preoperative anatomical analysis of the grafted RGEA in addition to the celiac/pancreaticoduodenal region is mandatory.

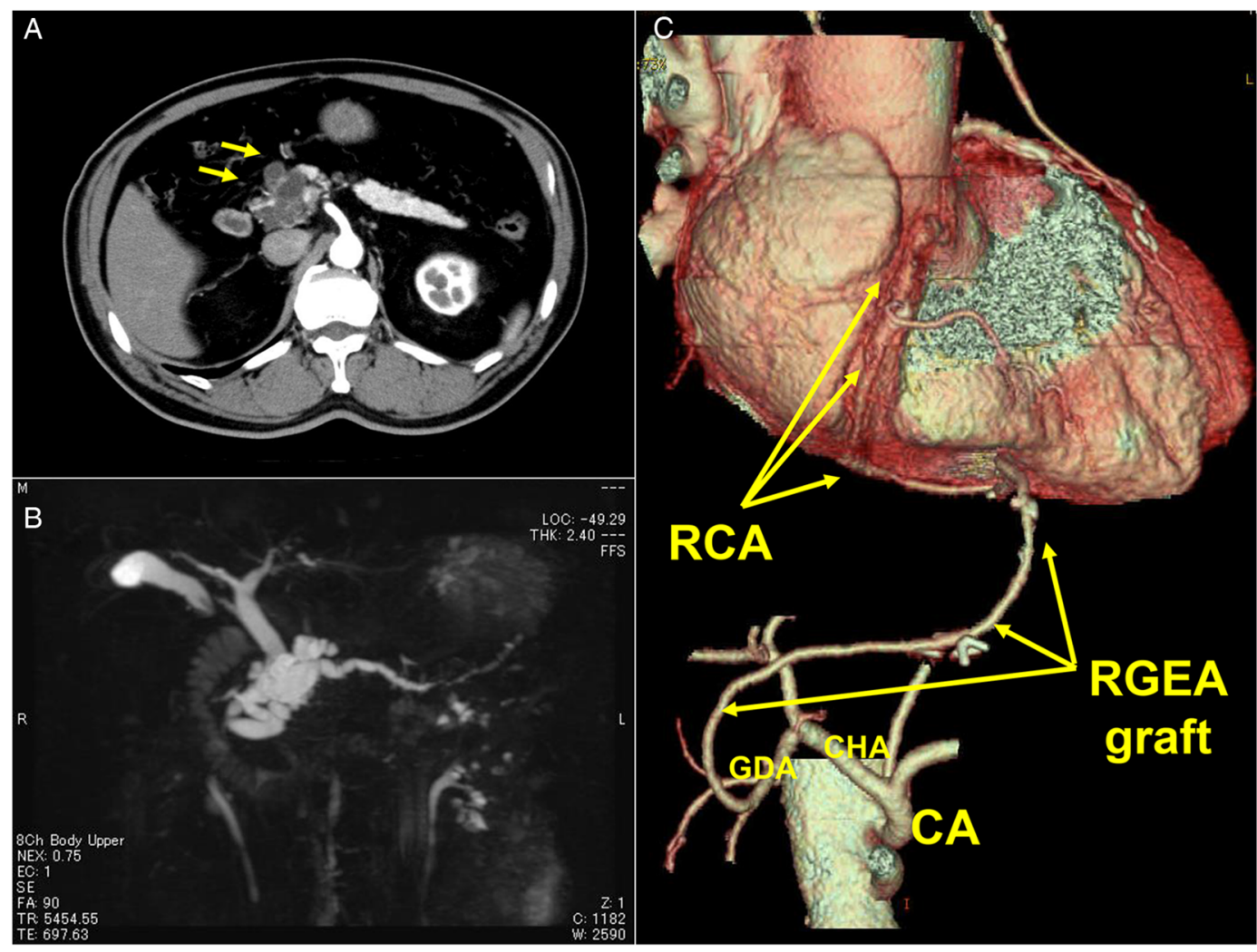

Figure 1 (A) Enhanced CT of the abdomen revealed a $4 \mathrm{~cm}$-sized multilocular cystic tumour of the pancreatic head (arrows), which was gradually enlarging during these 2 years and was suggestive of potentially malignant intraductal papillary mucinous tumour. (B) MR cholangiopancreatography also showed multiple cystic lesions in the pancreatic head and dilated main pancreatic duct. (C) Three-dimensional coronary CT showed patent RGEA graft connected to the right coronary artery. RCA, right coronary artery; RGEA, right gastroepiploic artery; CA, celiac axis; CHA, common hepatic artery; GDA, gastroduodenal artery. 


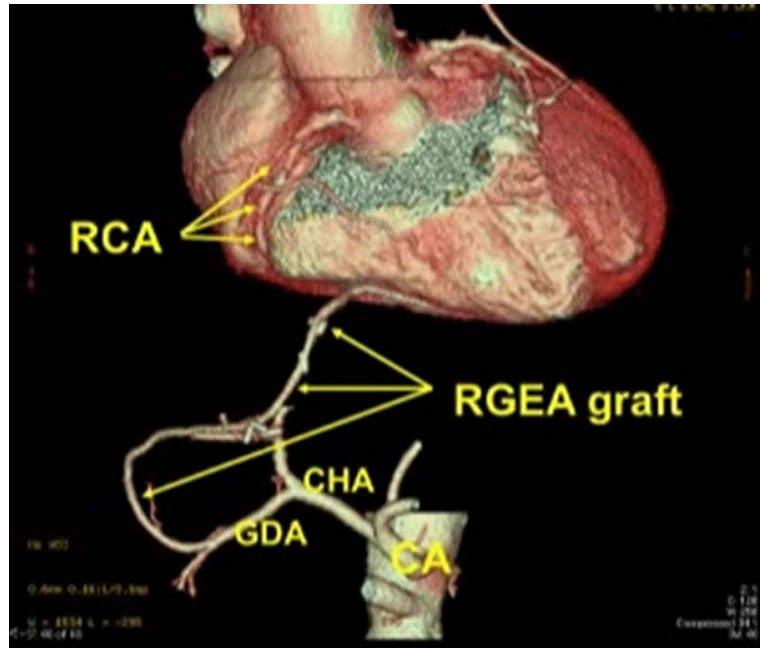

Video 1 Three-dimensional coronary CT showed patent RGEA graft connecting to the right coronary artery. Abbreviations: RCA, right coronary artery; RGEA, right gastroepiploic artery; $\mathrm{CA}$, celiac axis; $\mathrm{CHA}$, common hepatic artery; GDA, gastroduodenal artery.

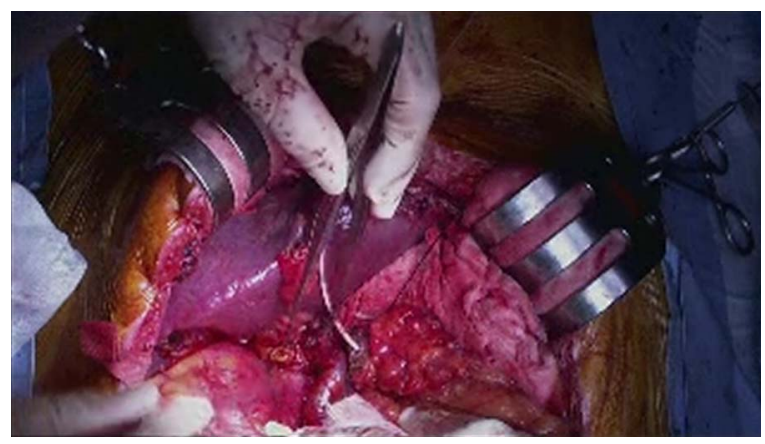

Video 2 Following successful native coronary revascularization, subtotal stomachpreserving pancreaticoduodenectomy by sacrificing RGEA was satisfactorily performed without any intraoperative cardiac complications.

Only three reports have described PD in the presence of grafted RGEA, ${ }^{1-3}$ in two of which RGEA was sacrificed and reconstructed using the saphenous vein. Such as in our case, preoperative native coronary revascularisation by CSI is one of the preferred options to ensure successful outcomes in case of performing PD after RGEA-grafted CABG.

\section{Learning points}

- Coronary artery bypass grafting (CABG) using the right gastroepiploic artery (RGEA) has been widely applied, but interruption of RGEA used for prior CABG may cause life-threatening myocardial ischaemia during upper abdominal surgery.

- When performing pancreaticoduodenectomy (PD) after RGEA grafted CABG, not only preoperative assessment of vascular anatomy, but also preservation of coronary arterial flow during the operation is requisite.

- Preoperative native coronary revascularisation by coronary stent implantation is one of the preferred options to ensure successful outcomes when performing PD after RGEA grafted $C A B G$, like the current case.

Contributors TF and NT operated and TF, NT and YA managed the patient perioperatively. TF prepared the manuscript and AT reviewed it.

Competing interests None.

Patient consent Obtained.

Provenance and peer review Not commissioned; externally peer reviewed.

\section{REFERENCES}

1 Mikawa K, Nishina K, Ando T, et al. Anesthesia for pancreatoduodenectomy in a patient with history of coronary artery bypass graft surgery: determination of optimal surgical management by the graft clamping test. J Clin Anesth 2007;19:222-5.

2 Nakamura N, Irie T, Ochiai T, et al. Pancreatoduodenectomy after coronary artery bypass grafting using the right gastroepiploic artery: a case report. Hepatogastroenterology 2011;58:1137-41.

3 Turcanu M, Addeo P, Rosso E, et al. Pancreaticoduodenectomy after coronary artery bypass grafting with use of an in situ right gastroepiploic artery graft. Eur $J$ Cardiothorac Surg 2013;44:382-3.

\footnotetext{
Copyright 2014 BMJ Publishing Group. All rights reserved. For permission to reuse any of this content visit http://group.bmi.com/group/rights-licensing/permissions.

BMJ Case Report Fellows may re-use this article for personal use and teaching without any further permission.

Become a Fellow of BMJ Case Reports today and you can:

- Submit as many cases as you like

- Enjoy fast sympathetic peer review and rapid publication of accepted articles

- Access all the published articles

- Re-use any of the published material for personal use and teaching without further permission

For information on Institutional Fellowships contact consortiasales@bmjgroup.com

Visit casereports.bmj.com for more articles like this and to become a Fellow
} 